IZA DP No. 10138

Is There a Role for Higher Education Institutions in Improving the Quality of First Employment?

Seamus McGuinness

Adele Whelan

Adele Bergin

August 2016 


\title{
Is There a Role for Higher Education Institutions in Improving the Quality of First Employment?
}

\author{
Seamus McGuinness \\ ESRI, Trinity College Dublin, NILS, Flinders University and IZA
}

Adele Whelan

ESRI and Trinity College Dublin

Adele Bergin

ESRI and Trinity College Dublin

\author{
Discussion Paper No. 10138 \\ August 2016
}

\author{
IZA \\ P.O. Box 7240 \\ 53072 Bonn \\ Germany \\ Phone: +49-228-3894-0 \\ Fax: +49-228-3894-180 \\ E-mail: iza@iza.org
}

\begin{abstract}
Any opinions expressed here are those of the author(s) and not those of IZA. Research published in this series may include views on policy, but the institute itself takes no institutional policy positions. The IZA research network is committed to the IZA Guiding Principles of Research Integrity.

The Institute for the Study of Labor (IZA) in Bonn is a local and virtual international research center and a place of communication between science, politics and business. IZA is an independent nonprofit organization supported by Deutsche Post Foundation. The center is associated with the University of Bonn and offers a stimulating research environment through its international network, workshops and conferences, data service, project support, research visits and doctoral program. IZA engages in (i) original and internationally competitive research in all fields of labor economics, (ii) development of policy concepts, and (iii) dissemination of research results and concepts to the interested public.
\end{abstract}

IZA Discussion Papers often represent preliminary work and are circulated to encourage discussion. Citation of such a paper should account for its provisional character. A revised version may be available directly from the author. 
IZA Discussion Paper No. 10138

August 2016

\section{ABSTRACT \\ Is There a Role for Higher Education Institutions in Improving the Quality of First Employment?}

This paper examines the potential role of higher education institutions in reducing labour market mismatch amongst new graduates. The research suggests that increasing the practical aspects of degree programmes, irrespective of the field of study, will reduce the incidence of initial mismatch. In terms of routes into the labour market, higher education work placements with the potential to develop into permanent posts and the provision of higher education job placement assistance were found to have substantial impacts in reducing the incidence of graduate mismatch. The use of private employment agencies was found to significantly heighten the risk of subsequent mismatch.

JEL Classification: J24, J31

Keywords: graduate labour market, overeducation, over-skilling, recruitment, course composition

Corresponding author:

Seamus McGuinness

Economic and Social Research Institute

Whitaker Square

Sir John Rogerson's Quay

Dublin 2

Ireland

E-mail: Seamus.McGuinness@esri.ie 


\section{Introduction}

The literature on labour market mismatch has expanded rapidly over recent decades (see Quintini, 2011 for a recent review). While little is known of the drivers of variations in cross country rates of mismatch (see Verhaest and Van der Velden, 2012 for a recent study exploring this issue) a good deal of evidence has emerged from the vast body of country specific research. The stylised facts suggest that mismatch has generally negative consequences for workers, resulting in both lower earnings and job satisfaction relative to their well-matched counterparts (Quintini, 2011; Sloane, 2003). Furthermore, research, such as that by McGuinness and Wooden (2009), suggests that while mismatched workers have higher rates of job mobility, they are more likely to move from one state of mismatch to another. There is also more recent evidence to support the view that mismatch has implications for firm level performance (Kampelmann and Rycx, 2012). Therefore, given this context, it is clearly important from a policy perspective that the problem of mismatch is tackled at the point of labour market entry to help ensure that workers do not incur long-run costs. This paper examines the transition from higher education to work among a cohort of European university graduates to determine the extent to which mismatch on labour market entry is determined by the route into employment and course composition of third-level degree programmes.

Labour market mismatch is generally measured in terms of overeducation ${ }^{1}$ within the existing literature, although the concept of overskilling ${ }^{2}$ is becoming more common as a measure of mismatch. Nevertheless, the bulk of the literature is centred around overeducation, which has been interpreted within the context of a number of theoretical labour market frameworks. For instance, overeducation is generally considered to be inconsistent with the human capital framework (Becker, 1964; Mincer, 1974) where labour markets are assumed to clear and workers earn their marginal product. Overeducation will only align with human capital theory (HCT) in the context of an omitted variables problem, whereby overeducation is proxying some deficiency in the human capital of workers, relative to their apparently matched counterparts, that has not been appropriately captured in the data ${ }^{3}$ (McGuinness, 2006). Conversely, both assignment theory (Sattinger, 1993) and the job competition model (Thurow, 1975) provide frameworks by which overeducation is understood as a mismatch between the characteristics of workers and the productivity requirements of the available distribution of jobs. Finally, overeducation can also be understood as a temporary issue arising as a consequence of information asymmetries or strategic behaviour by workers seeking more basic skills in their chosen professions, for example, signalling phenomenon (Spence, 1973) and occupational mobility theories (Sicherman, 1991; AlbaRamirez, 1993).

This study explores two particularly under-researched explanations for labour market mismatch: (a) that it may be a factor of the type, as opposed to the quantity of human capital accumulated and (b) that it may be partially driven by the fact that certain routes to the labour market are particularly ineffective in reducing informational asymmetries between the requirements of job seekers and employers. Given have influence over both factors, particular attention is paid to the potential role of universities in

\footnotetext{
${ }^{1}$ Overeducation reflects the extent to which individuals hold qualifications in excess of those required either to "get" or "do" their current job. Overeducation can be measured through both objective and subjective methods.

${ }^{2}$ Over-skilling reflects the fact that individuals feel that many of their skills and abilities are unused in their current employment. To date, overskilling has been measured exclusively through subjective methods.

${ }^{3}$ For example, if it transpires that overeducated workers have, on average, lower levels of on-the-job training and this variable is not captured in the data, then the overeducation pay penalty may reflect lower levels of job-related human capital.
} 
reducing the incidence of initial graduate mismatch. The existing literature on the issues of both human capital development and labour market transitions is extremely thin, in relation to the type of human capital accumulated. Robst (2007) distinguishes between specific and general degree programmes finding that the former including medicine, engineering and law are less likely to be mismatched than the latter which include arts-based degrees, but the consequences in the terms of reduced earnings from mismatch are greater than for the former. Mavromaras \& McGuinness (2012) find that over-skilled workers with a higher academic degree tend to have the highest persistence of mismatch, while workers with vocational education tend to exit mismatch rather quickly. Although this evidence is somewhat indirect, it is suggestive that rates of mismatch might differ according to level of applied content within degree programmes. With respect to routes into the labour market, Carroll and Tani (2014), using panel estimation, suggest that jobs found through university careers offices are associated with lower probability of over-education relative to jobs found through advertisements and personal contacts.

This study focuses on the labour market transitions of newly qualified European university graduates on the basis of consistent evidence that young labour market entrants are disproportionately more likely to become mismatched (Cedefop, 2010; McGuinness, Bergin \& Whelan, 2015). We explore the potential role of universities in determining the extent of graduate mismatch through both the manner in which human capital is developed within degree programmes and the part played by third-level institutions in smoothing the transition of graduates to the labour market. In terms of the literature, the paper contributes an analysis of the extent to which educational institutions can help eliminate mismatch through more effective human capital development and reducing information asymmetries between prospective workers and firms. Consequently, this work considers the relevance of both HCT and signalling theory to the overeducation debate.

Thus, to summarise, the paper will address key research questions in the following order and the potential role of higher education institutions within this context:

1) Is graduate mismatch related to the nature of the route into employment? Are certain modes of entry more heavily correlated with over-education or over-skilling?

2) To what extent is labour market mismatch related to the variations in the structure of degree university programmes?

We use the Flexible Professional in the Knowledge Society (REFLEX) data set published in 2010 which contains information on university graduates from 15 European countries who completed their degree programmes in 2000/1 and were subsequently surveyed in 2005. The dataset contains information (subjective measures) on the extent of both over-education and over-skilling in first and current employment. The Reflex data allows us to undertake an in-depth assessment of the link between mismatch in the first employment with information on the mode of entry and the structure of degree programme delivery. Specifically, in relation to graduates' transition from study to work, we consider ten alternative routes into the labour market and we are able to measure the balance between, for instance, formal lectures, internships, practical knowledge as opposed to theoretical knowledge etc. This analysis allows us to assess the extent to which a higher predominance towards work-based or practical learning (and study-related work experience) reduces the extent of mismatch. The paper focuses on first employment and controls for possible non-random selection with respect to both job 
search and course composition using matching estimation techniques (propensity score matching and dose response models). In addition, to examine the potential bias relating to unobserved individual heterogeneity, we test the sensitivity of our matching estimates to the presence of unobserved heterogeneity using the $\mathrm{MH}$ bound test statistic.

Our results show that higher education institutions may have an important role to play in combating labour market mismatch among graduates. With respect to course composition, the study provides clear evidence that a higher concentration of work-related components such as research projects, work placements, the acquisition of facts/practical knowledge and project/problem-based learning can reduce the probability of graduate mismatch in first employment. While the individual impacts were strongest for the provision of work placements and a focus on facts/practical knowledge, our research supports the view that there is a strong inverse relationship between the aggregate number of vocational course components in a degree programme and the probability of mismatch in first job. In terms of routes into the labour market, higher education work placements with the potential to develop into permanent posts and the provision of higher education job placement assistance have very substantial impacts in reducing the incidence of graduate overeducation. The research supports the view that by strengthening links with employers and investing more heavily in career-support functions, universities and third-level institutions can play an important role in matching graduates with jobs, thereby eliminating informational asymmetries and reducing the incidence of graduate mismatch.

These findings have relevant implications for policy, as they support an expanded role for higher education institutions in reducing labour market mismatch by (a) increasing the resources allocated to work placements and job matching services and (b) providing students with additional training in more effective job search methods. 


\section{Data and Methods}

The data used in this study is from the Flexible Professional in the Knowledge Society (REFLEX) project. This project was financed as a Specific Targeted Research Project (STREP) of the European Union's Sixth Framework Programme covering 15 countries. ${ }^{4}$ It is limited to graduates in the 1999/2000 academic year who were interviewed in 2005 and we examine their first job after graduation (transition from study to work). For the purpose of this study, we restrict our sample to individuals who studied for their third-level qualification on a full-time basis and we exclude those who were self-employed in their first job.

The literature has shown that both the determinants and impacts of labour market mismatch vary according to the type and severity experienced (Mavromaras et al., 2013), so we explore relationships with respect to four specific forms of mismatch. We classified graduate occupational mismatch into: 1) any form of mismatch 2) over-educated only, 3) over-skilled only, and 4) severely mismatched (both over-educated and over-skilled). Individuals were defined as over-educated if they indicated that the most appropriate level of education for their first job was below tertiary level. Over-skilling was based on the response to a question asking individuals to rate the extent to which their skills and knowledge were utilised in their work on a scale of 1 (not at all) to 5 (to a very high extent). A rating of 1 or 2 was deemed to be consistent with being over-skilled.

A unique feature of the REFLEX dataset is that in addition to collecting information on graduate mismatch, specific questions are asked in relation to the job search method used to find their first job and detailed information on course composition. In relation to their transition from study to work, the respondents were presented with a question on how they found their first job including a list of ten response options ${ }^{5}$ and were instructed to select one. In relation to their study programme, respondents were asked to what extent a list of eleven modes of teaching and learning ${ }^{6}$ were emphasised on a scale of 1 (not at all) to 5 (to a very high extent). A rating of 5 (to a very high extent) was deemed to be a course with high emphasis on this mode of course composition and our variables were constructed on this basis.

In terms of the methodological approach adopted here, we begin with an analysis of the impact of route into the labour market on mismatch and then proceed using the same techniques to examine the role of course content. We begin by estimating a standard probit model examining the effect of entry mode on graduate mismatch,

$$
M_{i}^{*}=\beta_{1} X_{i}+\beta_{2} D_{i}^{E M}+\varepsilon_{i}
$$

where $M_{i}$ is a latent variable which denotes an individual's probability of being mismatched in their first

\footnotetext{
${ }^{4}$ The countries included in this analysis are: Austria, Belgium, Finland, France, Germany, Italy, Netherlands, Norway, Portugal, Spain and the United Kingdom.

${ }^{5}$ The job search categories included through advertisement in a newspaper, through public employment agency, through private employment agency, through internet, contacted employer on own initiative, through work placement during higher education, through family, friend or acquaintances, through help of higher education institution or other.

${ }^{6}$ The course composition modes included lectures, group assignments, participation in research projects, internships/work placement, facts and practical knowledge, theories and paradigms, teacher as the main source of information, project and/or problem-based learning, written assignments, oral presentations by students, and multiple choice exams.
} 
job, $\mathrm{X}$ equals a vector of personal and job characteristics, $\mathrm{D}^{\mathrm{EM}}$ is a set of dummy variables measuring the mode of entry to the labour market and $\varepsilon_{\mathrm{i}}$ is an iid error term. We control for age, gender, field of study $^{7}$, education background, relative ability, family characteristics, job characteristics, migrant status and country. Subsequently, we perform the same analysis by separately using the individual's probability of being over-educated, over-skilled and severely mismatched (over-educated and overskilled) as the dependent variable to assess whether there are differential impacts depending on the nature of mismatch. The course composition impacts are estimated using the same approach with the entry mode dummies replaced by indicators of course content.

We undertake further analysis to examine potential biases relating to either sample selection and unobserved individual heterogeneity. If assignment to the various modes of labour market entry was in some way systematic, for example, individuals opting for a certain entry method also had observable characteristics that systematically influenced the probability of mismatch, then failure to take account of such non-random selection would bias the estimated impacts of the entry mode variables. We adopt a propensity score matching (PSM) model with control and treatment groups to overcome this estimation risk. The PSM approach ensures that treated individuals, in terms of the variables of interest, are compared with members of a non-treated control group who hold similar observable characteristics. PSM involves a two-stage process. In the first stage, the principle characteristics that influence the probability of being in the treatment and control groups are assigned a "propensity score" based on their estimated probability of receiving treatment (e.g. Public Employment Agency). The first stage equation controls for gender, age, relative ability, years of higher education, field of study, migrant status, parental education, work experience before higher education, country fixed effects and job characteristics including sector, hours of work and contract type variables. The propensity score is defined as the conditional probability of receiving a treatment given certain determining characteristics,

$$
p(X)=\operatorname{Pr}\{D=1 / X\}=E\{D / X\}
$$

where $D$ is a binary term indicating exposure to the treatment, in this case mode of study or job search method, and $X$ is a vector of determining characteristics. In the second stage, individuals in the treatment group are "matched" with counterparts in the control group that have similar propensity scores and their actual outcomes (mismatch) are compared. Rosenbaum and Ruben (1983) show that matching individuals on the basis of propensity scores is equivalent to matching on actual characteristics. There are a number of PSM algorithms that can be estimated but no single method is generally considered to be superior. In this instance, pairs of treated and untreated subjects are formed with individuals whose propensity scores differ by at most a pre-specified amount ${ }^{8}$; we employ a caliper width estimator.

The main limitations of the PSM approach are that (a) common support can be a problem and (b) the fact that matching helps control only for observable differences and not unobservable differences. As our estimated treatment effect is conditioned on the propensity score, we next check to ensure the assumption that this is equivalent to conditioning on the individual covariates was met by testing that

\footnotetext{
7 We distinguish a maximum of seven fields of study for each country: (i) education, humanities and arts, (ii) social sciences, business and law, (iii) science, mathematics and computing, (iv) engineering, manufacturing, and construction, (v) health and welfare, (vi) agriculture and veterinary, and (vii) services. Therefore, the reported effects are over and above those related to field of study.

8 The appropriate caliper depends to some extent on the data set to which it is being applied; it should be tight enough to produce close matches for efficiency, but not so tight that it becomes impossible to match a number of treated individuals, which could introduce both inefficiency (due to the reduced sample size) and selection bias. We started with a caliper of 0.1 and tightened in some cases to 0.05 until we were content with our post-estimation checks that our data were well-balanced.
} 
all observable differences between the control and treatment groups have been eradicated postmatching. Our post-estimation check ensures that statistically significant differences within individual characteristics across the treated and untreated samples are eliminated post-matching. Before matching differences are expected, but after matching the covariates should be balanced in both groups and hence no significant differences in covariate means should be found. This ensures that any additional conditioning on observable characteristics will not provide any new information on the treatment decision. Specifically, we measure the extent to which the pseudo $\mathrm{R}^{2}$ of the stage 1 probit falls towards zero when estimated on the matched sample, indicating that there remain no systematic differences in the distribution of the covariates between both groups (treatment and control).

The second potential concern relates to selection on unobservables which our PSM approach does not directly address. Therefore, further sensitivity analysis is then applied to our PSM estimates to ensure that they are free from the effects of individual unobserved heterogeneity bias. The reliability of any propensity score matching estimate is dependent upon the Conditional Independence Assumption (CIA) being met i.e. that selection to the treatment is based solely on observables within the dataset and where all variables that simultaneously impact both the treatment and outcome variable are also observed. Given that the REFLEX data contains information of a wide range of personal, job and background characteristics, that are included in our first stage model, we are confident that the variables at hand sufficiently incorporate all key aspects of the allocation to treatment processes. Nevertheless, despite this, it is not possible to completely rule out the possibility that our estimates are unaffected by one or more unobserved effects that simultaneously influence both the treatment and outcome variables. While we cannot explicitly eliminate such influences, as we might do for instance by estimating a fixed effects model within a panel environment, we can test the sensitivity of our estimated treatment effects to the existence of such hidden bias. Our broad job search and course composition PSM estimates are checked for robustness to unobserved heterogeneity bias using the "mhbounds" procedure in Stata (see Becker and Caliendo, 2007). This allows us to introduce an unobserved factor that simultaneously increases the likelihood of mismatch and increases the likelihood of allocation to the treatment group (termed positive selection bias) to assess if our estimated treatment effect remains statistically reliable. In our results section, our tables include the post-estimation $\mathrm{MH}$ bound test statistics and we distinguish between the estimated effects that are robust to unobserved heterogeneity bias (on the basis of the $\mathrm{MH}$ bound test statistic) and those which are likely to be more questionable.

Furthermore, we attempt to gain a greater insight into the role of course composition by allowing for non-linear impacts by estimating a dose response function (DRF) (Hirano and Imbens, 2004). The DRF measures the impact of various doses of the treatment (in this case, vocational aspects of course composition) on subsequent mismatch within first job. The eleven course composition variables, asking respondents on the extent to which certain modes were emphasised on a scale of 1 to 5, are grouped into vocational categories to derive continuous measures. ${ }^{9}$ Assuming that the weighting reflects the dose, we can investigate whether the likelihood of a match in first employment is sensitive to the "dose" of vocational or educational training within the degree programme. The dose response functions are estimated on the treated sample using the generalised propensity score (GPS). The GPS methodology separates treated individuals into segments related to their exposure to the treatment, in this instance the emphasis on certain modes of course composition, and assumes that individuals within each strata

\footnotetext{
${ }^{9}$ For vocational aspects we sum together a score from participation in research projects, internships/work placement, facts and practical knowledge, and project and/or problem-based learning (i.e. a maximum score of 20). Non-vocational aspects were assumed to relate to lectures, group assignments, theories and paradigms, teacher as the main source of information, written assignments, oral presentations by students, and multiple choice exams.
} 
of the GPS should have identical characteristics based on their propensity scores with respect to receiving treatment. The approach ensures that assignment to course composition is random with respect to dose. The GPS methodology consists of three steps. In step one, letting $r(t, x)=f_{T \mid X}(t \mid x)$ be the conditional density of the treatment given the covariates the Generalized Propensity Score (R) is defined as,

$$
R=r(T, X),
$$

and the data balanced both within and between intervals. In the second step, the relationship between the outcome variable (mismatch), course composition dose and the GPS is estimated. The second step is to estimate the conditional expectation of the outcome variable (mismatch) as a function of two scalar variables, the course composition dose (T) and the GPS (R), estimated as,

$$
\beta(t, r)=E\{Y \mid T=t, R=r\}
$$

In the third step, the DRF is estimated by averaging the conditional expectation of mismatch over the GPS at each level of treatment. ${ }^{10}$ This is implemented by averaging the conditional expectation function over the GPS at that particular level of the treatment,

$$
\mu(t)=E[\beta(t, r(t, X))]
$$

Given that the number of individuals who had no academic components within their degree programme is very low, the lack of an effective control group excludes the possibility of estimating a dose response model for non-vocational course intensity.

${ }^{10}$ We use the Stata procedure "doseresponse" developed by Bia and Mattei (2008). 


\section{Descriptive Statistics}

The rates of mismatch, shown in Table 1, vary across countries from $9 \%$ in Portugal to $43 \%$ in the UK with an overall average of $23 \%$. This total figure was composed of those who were over-educated only (ranging from $1 \%$ to $11 \%$ ), over-skilled only (ranging from $3 \%$ to $15 \%$ ) and severely mismatched (ranging from 3\% to 24\%). Spain and the UK are shown to be outliers in the terms of mismatch incidence and this is shown in many papers including McGuinness et al. (2015), Flisi et al. (2014) and Pouliakas (2013). An explanation for this may lie with relatively high participation levels of third level participation. However, there is very little research on cross country variations to date. As a result of our exclusions, ${ }^{11}$ the effective sample falls from 34,347 to 18,145 . Individual country samples range from 438 in Portugal to 3,092 in Spain. ${ }^{12}$

Across countries mismatch was generally lowest in the health and welfare sector and highest in humanities and arts (34\%), services (33\%), social science and business (31\%), and science and maths $(25 \%) .{ }^{13}$ In relation to graduates' routes into the labour market, the majority $(20 \%)$ contacted the employer directly while public employment agencies (5\%), private employment agencies (5\%) and help from higher education (6\%) were used to a much lesser extent ${ }^{14}$. Differences across countries were evident, with regard to entry mode, with Italian and Spanish students much more likely to use their network of family and friends to obtain their first job than Dutch or Belgian graduates. Help from higher education institutions were particularly important in Belgium and Italy. Dutch students were much more likely to obtain a higher education work placement and use a private employment agency (along with the UK) than graduates from other countries. In Portugal, compared to other countries, it was more likely that graduates would be approached by employers directly.

Across different types of mismatch, it appears that those who are severely mismatched are more likely to use private employment agencies and their networks of family and friends (Table 2). In relation to the modes of course composition emphasised, lectures (30\%) and theories and paradigms (17\%) were emphasised to a much higher degree than research projects (4\%) and MCQ exams (5\%). ${ }^{15}$ The UK appears to place a particular focus on lectures (along with Belgium) and written assignments while the Netherlands, Portugal, Finland and Germany are more likely, than other countries, to have a work placement as part of their courses. The distribution of vocational courses across countries (Table 3) shows that an average of $39 \%$ of courses are vocational courses across all countries. However, Finland (62\%), Norway (60\%), and the Netherlands (57\%) have a much higher proportion of vocational courses than the other countries in our sample.

\footnotetext{
${ }^{11}$ We focus on 11 countries (Austria, Belgium, Finland, France, Germany, Italy, Netherlands, Norway, Portugal, Spain and the United Kingdom) and restrict our sample to individuals who studied for their third-level qualification on a full-time basis and who are currently employed.

12 Table including means of all the variables used with their full definitions available on request from authors.

13 Table available on request from authors.

14 Table available on request from authors.

15 Table available on request from authors.
} 


\section{Route into the Labour Market}

We investigate the impact of various routes into the labour market on the probability of being either over-educated or over-skilled by estimating a standard probit model that simultaneously controls for a range of factors including route into the labour market. It must be borne in mind that, in the data, we only observe the one search method used by each respondent to secure their first employment, which does not preclude the possibility that individuals had simultaneously, or sequentially, employed a range of search techniques before securing their job.

For brevity, we present only the coefficients for the entry mode variables in Table 4 derived from the standard probit and the propensity score models. ${ }^{16}$ The reference category in the probit models is "contacted the employed directly" and, for the purposes of consistency the PSM estimates were also generated relative to this reference category. ${ }^{17}$ Concentrating on the results from the probit model (Table 4), there is evidence to suggest that the route into an initial job is an important determinant of mismatch. Relative to the base case of contacting the employer directly, individuals obtaining their first jobs through a private employment agency were 18 percentage points more likely to be mismatched. This large impact would suggest that private agencies are, perhaps, more concerned with generating a fee and tend to place less emphasis on the quality of the match. Graduates who obtained their first job by responding to advertisements, contacting public employment agencies, and through family and friends were between six and seven percentage points more likely to be mismatched relative to the reference category. However, a number of routes to the labour market actively reduce the likelihood of mismatch. In particular, the results highlight the importance of higher education (HE) institutions in the job matching process, where jobs acquired with the help of the university or as a result of a higher education work placement reduce the probability of mismatch by between seven and eight percentage points. Furthermore, those individuals indicating that they had obtained their first position with the help of their HE institution were also approximately 7 percentage points less likely to be mismatched. These results confirm that third-level institutions have the potential to make substantial inroads into the problem of graduate mismatch by increasing the resources allocated to post-graduation job placements. Finally, graduates who were approached by employers were six percentage points less likely to be mismatched, while those who entered the labour market through other routes were five percentage points less likely to be mismatched. In terms of the impact of the other control variables, the results generally conform to expectations with all forms of mismatch generally negatively correlated with being male, relative grade achieved, years spent studying in higher education and hours worked. The likelihood of mismatch was generally positively correlated with having studied in the fields of education and humanities and consistent with the descriptive analysis, mismatch was generally lower (relative to the German base case) in Portugal and higher in Spain.

\footnotetext{
${ }^{16}$ The full probit model results and the results from the stage one equation from the PSM are available from the authors.

${ }^{17}$ For example, the public employment agency PSM estimate was derived from a sample restricted to individuals who had gained their first job through either a public employment agency or by contacting their employer directly.
} 
The results from the PSM analysis align closely to those generated by the probit model, suggesting that non-random selection into mode of entry did not impact the results. The one exception relates to finding the job through the internet, which generates a negative and significant coefficient in the PSM analysis only. The results of the stage one models from the PSM analysis are themselves informative. Males were slightly more likely to have entered their first job via family and friends or having been approached by an employer or through HE assistance. Graduates with higher relative grades were also more likely to enter the labour market as a consequence of contacts from employer, higher education work placement or assistance from their higher education institution, suggesting that both firms and universities tend to target the most able students for job placements. The motivation for such "cherry picking" on behalf of employers is obvious, however, the result suggests that maintaining reputational integrity may be a factor in university instigated placements. Interestingly, students from backgrounds other than education and humanities were much more likely to receive help in finding initial employment from their HE institution. Some further noteworthy patterns are observed with respect to subject area. Relative to the base case of education and humanities, graduates from science, engineering and agriculturallveterinary backgrounds are much more likely to have obtained their first job as a consequence of a previous HE work placement. Agricultural and veterinary graduates were most likely to have secured employment following an approach from an employer. Graduates from a science background were more likely to have found their first job via the internet. Finally, socio-economic background appears to play a role, graduates with a professional father were more likely to have obtained employment through family and friends, while a professional mother was correlated with having gained employment with the assistance of the HE institution.

In order to ensure the quality of our matching, we undertook a number of robustness checks. The third and fourth columns of Table 4 report the pseudo $\mathrm{R}^{2}$ statistics of the stage one PSM models, which identify the key characteristics distinguishing individuals pursuing a particular type of job search from those in the reference category who contacted the employer directly. The pre-matching pseudo $\mathrm{R}^{2}$ is a measure of the difference in observable characteristics between the treated (advert, public employment agency, internet etc.) and comparison group (contacted employer directly) that exist prior to matching taking place. Effective matching implies that observable differences between the two groups are eradicated and should no longer be statistically significant when the stage one probit model is reestimated on the matched sample. Thus a strong indicator that important differences in observables between the treated and comparison groups have been eradicated is that the pseudo $\mathrm{R}^{2}$ of a probit model estimated on the matched sample should be close to zero and statistically insignificant. The post-matching pseudo $\mathrm{R}^{2}$ statistics are reported in the fourth column of Table 4 and indicate that the matching on observables was successful.

We next check for robustness to unobserved individual heterogeneity by applying the mhbounds sensitivity procedure to the PSM estimates. Essentially, this test measures the extent to which an unobserved factor must increase the odds that an individual will be assigned to the treatment group before the estimated impact of the treatment becomes unreliable. For example, an $\mathrm{MH}$ bound test statistic of 2 indicates that an unobserved variable would have to be important enough to double the odds ratio that an individual would receive the treatment before the estimated impact becomes is statistically insignificant. The results from the sensitivity tests are somewhat mixed. The 18 percentage point estimate for private employment agency job search is highly robust, given that an unobserved 
factor would have to be substantial enough to triple the odds that a graduate would enter the labour market via a private employment agency before the estimated positive treatment effect becomes suspect. Conversely, the estimated effects for some of the other variables are less robust to unobserved individual heterogeneity. For example, an unobserved influence would need to be sufficiently strong to increase the odds that a person would find their jobs through an advert or the internet by 20 and 5 percent respectively before the estimated treatment effects for these entry modes would be deemed unreliable. The remaining statistically significant PSM estimates are somewhat more robust and would require an unobserved factor to change the odds of receiving a treatment by between 50 to 100 percent before they lose significance. However, it is likely unobserved differences in ability and motivation will be more relevant for those entering the labour market with the assistance of $\mathrm{HE}$ institutions. While we do control explicitly for relative ability in our models ${ }^{18}$, motivation remains unobserved. The potential impact of unobserved ability and motivation on the respective odds ratios remains unknown, making it difficult to come to any solid conclusions regarding the robustness of the $\mathrm{HE}$ related estimates. Therefore, while we are confident that our data is sufficient to capture the principal characteristics that determine an individual's route to the labour market, we cannot rule out that some of the results with lower $\mathrm{MH}$ bound critical values might no longer be evident in the presence of some substantial, but as yet unobserved, factors.

In Table 5 we examine the extent to which the impact of route to the labour market varies by type of mismatch. We focus solely on PSM estimates on the basis that we believe this to be more reliable than naive probit models. The mismatch categories are over-educated only, over-skilled only and severely mismatched (both over-educated and over-skilled). Research to date suggests that the impacts of mismatch on labour market outcomes, such as earnings and job satisfaction, tend to vary according to the form of mismatch experienced. Over-education tends to be associated with a larger earning disadvantage but a lower job satisfaction deficit relative to over-skilling only, while, severely mismatched workers tend to experience both low earnings and job satisfaction levels relative to the being overeducated or over-skilled only (Mavromaras et al., 2013). In terms of both marginal effects and significance levels, some differential patterns are observed. On the whole, route to the labour market appears least important for avoiding over-education only. Route to the labour market is somewhat more important for over-skilling, with the observed impacts most evident with regard to severe mismatch. A number of job entry variables are significant across all forms of mismatch, for instance, the use of private employment agencies raises the probability of all types of mismatch, while HE placement, approached by employers and the use of internet lower it. The results from Table 5 suggest that the general impacts observed for total mismatch in Table 4 are heavily driven by the impact of job-entry mode on the probability severe mismatch. The results suggest that the incidence of severe mismatch, which is associated with the largest pay and job satisfaction penalties, might be reduced by directing graduates away from certain methods of job search.

Finally, the data allows us to assess the extent to which the impacts of the route into the labour market varied according to the time elapsed since graduation. Unfortunately, the information available was such that we could only distinguish between those to obtained their first employment pre and post the three month post-graduation point. Nevertheless, this distinction is useful as the three month estimates

${ }^{18}$ Respondents are asked to rank their course score relative to the course average. 
allow for a more precise estimate of the impact of job search on mismatch on the grounds that it is less likely that graduates will have engaged in more than one form of job-search within that period. Table 6 indicated that while the impacts do not vary substantially across the two time periods, some variations are worthy of note. The use of public employment agencies (internet) only raises (lowers) the likelihood of mismatch immediately following graduation. It also seems that using family and friends as a route into the labour market tends to raise the probability of mismatch somewhat more beyond the three month post-graduation point, perhaps indicating that graduates may resort to this route only after other forms of job-search have proven unsuccessful. 


\section{Course Composition}

We next explore the extent to which the composition of the degree programme impacts the subsequent likelihood of mismatch. Variations in course composition are likely to impact the amount of work-related human capital accumulated by students, which will subsequently impact their attractiveness to potential employers and/or their ability to identify an effective match. Following the approach adopted for the mode of labour market entry analysis, Table 7 presents the course composition coefficients from both probit models and PSM estimates, where the dependant (outcome variable) was again binary in nature and indicated that the graduate was exposed to any form of mismatch in their first job. ${ }^{19}$ It should be noted that, as the different forms of course composition are not mutually exclusive, the estimates do not relate to any particular reference category. Both the probit and PSM methods indicate that students who undertook courses which had a heavy emphasis on work placements and practical knowledge were between six and nine percentage points less likely to be mismatched in their first job. The analysis also indicates that a heavy emphasis on written assignments raises the likelihood of mismatch by three percentage points. Comparing the two estimation methodologies, an emphasis on oral presentations by students and multiple choice exams were found to raise the probability of mismatch, at a ten per cent level of confidence, under the probit analysis only and the estimate was not significant for PSM estimate. The PSM framework alone generated a negative and significant impact for problem-based learning and a positive impact for an emphasis on theories and paradigms. Although there are some variations in the PSM and probit estimates, the general trend in the results suggests that a heavy emphasis on more vocational components tends to lower the likelihood of mismatch, whereas a focus on more theoretical elements tends to raise it.

The stage one equations from the PSM analysis are insightful as they highlight the key characteristics of individuals undertaking degree programs with particular characteristics. Some gender differences are apparent, with females more likely to take degrees with a high emphasis on lectures and written assignments. Relative grade is generally positively associated with most course elements; however, the marginal effects are also higher for courses with more emphasis on lectures and written assignments. ${ }^{20}$ Course duration appears to be a relevant factor, with shorter duration programmes likely to place a heavier emphasis on theories/paradigms and less likely to offer a work placement. In terms of field of study a number of interesting insights are gained. Relative to the base case of education and humanities, degree programmes generally perceived as vocational, such as degree in science, engineering, agriculturelveterinary, were found to place a much higher emphasis on lectures. The focus on group assignments was less common in the vocational subject areas, while the use of research projects was more common in science courses. The probability of work placement was highest for courses in health and services but, somewhat surprisingly, lowest for programmes in science and engineering. Health courses tended to have a higher focus on facts and practical knowledge, while problem-based approaches to learning were emphasised more in engineering and service degrees. Theories and paradigms were most important (least) in social science and science (agriculturelveterinary and service courses), while degrees in education and humanities placed the most emphasis on written assignments.

\footnotetext{
${ }^{19}$ The results from full probit model and the stage one equations from the PSM are available from the authors.

${ }^{20}$ Reverse causation is a possible factor here if it is easier to obtain higher relative grades by taking courses with such attributes.
} 
To the extent that the probit and PSM estimates deviate slightly, the PSM analysis is preferred as it will explicitly control for any non-random selection on the observables contained in the data. The post matching pseudo $\mathrm{R}^{2}$ statistics are all close to zero and are not statistically different from zero, indicating that the quality of our matching was good and that all important differences in the observable characteristics of the treated and non-treated groups were eliminated. In terms of the robustness of the statistically significant treatment effects to unobserved factors, the $\mathrm{MH}$ bound tes statistics indicated that the work placement result is relatively robust ${ }^{21}$, however, the impacts regarding practical knowledge, work-based learning and written assignments may be somewhat less reliable with regard to unobserved heterogeneity ${ }^{22}$. Therefore, while we are confident of the quality of the data and the matching underlying the PSM estimates, some caution is again required with respect to the robustness of the majority of the estimated course composition effects with respect to unobservables.

Table 8 examines the extent to which the impacts of degree composition vary depending upon the nature of mismatch experienced. The results shown are generated by PSM. A high emphasis on both work placements and the acquisition of practical knowledge reduces the likelihood of all forms of mismatch. However, the marginal impacts are smaller with respect to avoiding over-education. An emphasis on theories and paradigms was found to reduce the likelihood of over-education and raise the probability of over-skilling. On the other hand, an emphasis on group assignments was found to raise the likelihood of over-education and reduce the probability of over-skilling. A focus on written assignments had a positive impact on the probability of both over-education and severe mismatch with no impact evident for over-skilling, while a heavy emphasis on oral presentations by students raised the likelihood of overeducation only. Finally, a concentration on project-based learning had the effect of lowering the probability of severe mismatch alone.

Elements of each teaching component are likely to be present, to varying extents, in both vocationally and academically orientated degrees and Table 8 tests the differential impact of each measure on the likelihood of mismatch using this broad dichotomy. Within the REFLEX data, respondents were asked to rate, on a scale of one to $5^{23}$, the extent to which their degree programme was vocationally orientated. Individuals ranking their degree programme at 4 or 5 were deemed, by us, to be undertaking a broadly vocational degree with the remaining respondents assumed to be undertaking a broadly academic degree. We estimated our models separately for each grouping and Table 9 indicates that there are very substantial benefits, with respect to reducing the incidence of mismatch, to including work placements and a more defined emphasis on project based learning in academically orientated degrees. Specifically, the existence of a work placement within an academic degree reduces the probability of subsequent mismatch in first employment by 12 percentage points.

\footnotetext{
${ }^{21}$ The result suggests that an unobserved factor would have to more than double the odds of a graduate undertaking a programme with a heavy emphasis on work placements for the estimated impact of work placement on mismatch to become insignificant.

${ }^{22}$ Should an unobserved factor be sufficiently important so that it raises the odds of the treatments by between 25 and 40 per cent the estimated impacts will become insignificant.

${ }^{23}$ Where 1 represented "not at all" and 5 to a "very high extent".
} 
The use of binary variables focused on specific course components does not allow us any insight into the extent to which a higher overall emphasis on work-related education impacts the likelihood of mismatch relative to more academically focused degrees. Given that survey respondents were asked to rate the degree of emphasis on each course component from 1 to 5 , we can treat these variables as a continuous measure of the extent to which a particular element was present within the degree structure. By classifying each component as either vocational or academic in nature and summing over both categories, we can assess the extent to which mismatch varied according to the general emphasis placed on vocational components within the degree programme. Under this approach, research projects, work placements, the acquisition of facts/practical knowledge and project/problem-based learning are classified as work-related or vocational degree components with the remaining seven elements classified as academic. The vocational emphasis measure will vary from 0 to 20 for each respondent. We assess the impact of the level of vocational orientation on labour market mismatch by estimating dose response models that allow us to measure the extent to which the probability of mismatch varies with an increase "dose" of each element while simultaneously controlling for the impacts of selection. In essence, the methodology matches individuals with a particular exposure to the treatment with non-treated counterparts with a similar probability (based on their observable characteristics) of receiving a like dose. Due to limitations on the sample size on which the dose response algorithm can be estimated, we were forced to estimate the models separately for males and females. The results are reported in Figures 1. Furthermore, as previously stated, due to a lack of respondents with no academic components within their degree, the absence of an appropriate control group excluded the possibility of estimating similar models for the overall impact of academic orientation.

The results clearly indicate that, for both genders, the probability of mismatch declines in a linear fashion the higher the total vocational emphasis of the degree program. For both males and females, the dose response function follows a clear linear trend with a relatively narrow upper and lower bound. In general, our analysis provides evidence that increasing the vocational/practical elements of a degree that has a significant and cumulative impact on the subsequent probability that graduates will be mismatched in their first job. 


\section{Summary and Conclusions}

The paper uses REFLEX data to examine the impact of both routes into the labour market and course composition on the likelihood that graduates in Europe will become mismatched in their first job. The rational for the study is that, given the evidence that labour market mismatch tends to be persistent even in the presence of high levels of job mobility, identifying factors that can impact initial mismatch provides opportunities to reduce both the overall incidence and long-run effects of labour market mismatch. As a result, third-level institutions represent a potentially important policy tool in reducing the incidence of mismatch among newly qualified graduates. The results of the study support the view the higher education institutions have an important role to play in combating labour market mismatch among graduates

In terms of routes into the labour market, higher education work placements with the potential to develop into permanent posts and the provision of higher education job placement assistance have very substantial impacts in reducing the incidence of graduate overeducation. The research supports the view that by strengthening links with employers and investing more heavily in career-support functions, universities and third-level institutions can play an important role in matching graduates with jobs, thereby eliminating informational asymmetries and reducing the incidence of graduate mismatch. Higher education institutions can also play an important role in terms of educating students in job search methods. It is clear from our results that the use of private employment agencies significantly heighten the risk of subsequent mismatch, perhaps due to the fact that such organisations are primarily motivated by achieving a job placement and have little incentive, or capacity, to ensure the quality of any match. More research is required into the role of job search on first employment and the long-run impacts of various routes to the labour market. The findings of such studies should then be communicated to students in the form of more systematic job search assistance designed to increase the quality of initial employment and, thereby, limiting the likelihood of labour market mismatch and its potential long-run negative impacts on both earnings and job satisfaction.

With respect to course composition, the study provides clear evidence that a higher concentration of work-related components such as work placements, the acquisition of facts and practical knowledge, project/problem-based learning and research projects can reduce the probability of graduate mismatch in first employment. While the individual impacts were strongest for the provision of work placements and a focus on facts/practical knowledge, our research supports the view that there is a strong inverse relationship between the aggregate number of vocational course components in a degree programme and the probability of mismatch in first job. The pay-off to increasing the practical aspects of programme delivery appear largest in degree courses generally classified as more academic in nature.

Finally, from the perspective of theory, the results of this study appear to confirm the views that labour market mismatch is, to some extent, explained as a consequence of (a) variations in the composition of human capital accumulated within formal educational settings and (b) the use of job search methods that fail to sufficiently reduce informational existing asymmetries between employers and workers. 


\section{Bibliography}

Alba-Ramirez, A. (1993). "Mismatch in the Spanish Labor Market." Journal of Human Resources 28(2): 259-78.

Becker, G. S. (1964). Human Capital, a Theoretical and Empirical Analysis, with Special Reference to Education. Columbia University Press, New York.

Becker, S. and Caliendo, M. (2007). "Sensitivity analysis for average treatment effects", The Stata Journal, Vol. 7, No. 1, pp. 71-83.

Bia, M. and Mattie, A. (2008). "A Stata Package for the Estimation of the Dose-Response Function Through Adjustment for the Generalized Propensity Score", The Stata Journal, Vol. 8, No. 3, pp. 354373.

Carroll, D. and Tani, M. (2014) "Job Search as a Determinant of Graduate Over-education: Evidence from Australia", Education Economics, forthcoming.

Cedefop (2010). The skill matching challenge - Analysing skill mismatch and policy implications. Luxembourg: Publications Office of the European Union.

Flisi, S., Goglio, V., Meroni, E., Rodrigues, M. \& Vera-Toscano, E. (2014). Occupational mismatch in Europe: Understanding Overeducation and Overskilling for Policy Making. JRC Science and Policy reports, European Commission, Luxemburg, ISSN 1831-9424.

Hirano, K., and G. W. Imbens. (2004). "The Propensity Score with Continuous Treatments" in A. Gelman and X.-L. Meng (eds.), Applied Bayesian Modelling and Causal Inference from IncompleteData Perspectives. West Sussex, England: Wiley InterScience.

Kampelmann, S. and F. Rycx. (2012). "The Impact of Educational Mismatch on Firm Productivity: Evidence from Linked Panel Data" Economics of Education Review, Vol. 31, No. 6, pp. 918-931.

Mavromaras, K,. McGuinness, S, O'Leary, N., Sloane, P, \& Wei, Z. (2013) “Job Mismatches and Labour Market Outcomes: Panel Evidence on Australian University Graduates", Economic Record, 2013, Vol. 89 (286), pp. 382-395.

Mavromaras, K. and McGuinness, S. (2012). 'Overskilling Dynamics and Education Pathways', Economics of Education Review, Vol. 31, No. 5, pp. 619-628.

McGuinness, S. (2006) "Overeducation in the Labour Market", Journal of Economic Surveys, Vol. 20, No. 3, pp. 387-418.

McGuinness, S., A. Bergin and A. Whelan (2015) A Comparative Time Series Analysis of Overeducation in Europe: Is there a common policy approach? STYLE Working Papers, WP 5.1. CROME, University of Brighton, Brighton. http://www.style-research.eu/publications/working-papers/

McGuinness, S. and Wooden, M. (2009). "Overskilling, Job Insecurity, and Career Mobility", Industrial Relations: A Journal of Economy and Society, Vol. 48, No. 2, pp. 265-286. 
Mincer, J. (1974). Schooling, experience and earnings, National Bureau of Economic Research, New York.

Pouliakas, K. (2013). "The Skill Mismatch Challenge in Europe", chapter 6 in Employment and Social Developments in Europe 2012. Luxembourg: Publications Office of the European Union.

Quintini, G. (2011). Over-qualified or Under-skilled: A review of the existing literature. OECD Social, Employment and Migration working papers No.121.

Rosenbaum, P. and D. Ruben. (1983). "The Central Role of the Propensity Score in Observational Studies for Causal Effects", Biometrika, Vol. 70, No. 1, pp. 41-55.

Robst, J. (2007). "Education and job match: The relatedness of college major and work", Economics of Education Review, Vol. 26, No. 1, pp. 397-407.

Sattinger, M. (1993). Assignment models of the distribution of earnings. Journal of Economic Literature, Vol. 31, No. 2, pp. 851-880.

Sicherman, N. (1991). "Overeducation in the Labor Market." Journal of Labor Economics, Vol. 9, No. 2, pp. 101-22.

Spence, M. A. (1973). "Job Market Signalling”. Quarterly Journal of Economics, Vol. 87, No. 3, pp. 35374.

Sloane, P. (2003). Much ado about nothing? What does the overeducation literature really tell us. In Buchel, de Grip and Mertens (eds), Overeducation in Europe (pp. 11-49). Cheltenham: Edward Elgar.

Thurow, L. (1975). Generating Inequality. New York: Basic Books.

Verhaest and Rolf Van der Velden (2013). Cross-country Differences in Graduate Overeducation. European Sociological Review , No. 29, pp 642-653. 


\section{Tables}

Table 1: Graduates Mismatched in First Job by Country, \%

\begin{tabular}{|c|c|c|c|c|c|c|c|c|c|c|c|c|}
\hline & Austria & Belgium & Finland & France & Germany & Italy & Netherlands & Norway & Portugal & Spain & UK & Total \\
\hline Over-Educated Only & 0.09 & 0.01 & 0.09 & 0.02 & 0.03 & 0.09 & 0.09 & 0.04 & 0.03 & 0.10 & 0.11 & 0.07 \\
\hline Over-Skilled Only & 0.07 & 0.15 & 0.06 & 0.13 & 0.10 & 0.08 & 0.08 & 0.05 & 0.03 & 0.08 & 0.08 & 0.08 \\
\hline Severely Mismatched & 0.06 & 0.05 & 0.05 & 0.06 & 0.03 & 0.11 & 0.09 & 0.03 & 0.03 & 0.20 & 0.24 & 0.10 \\
\hline Mismatched (sum of the above) & 0.22 & 0.21 & 0.20 & 0.21 & 0.15 & 0.28 & 0.26 & 0.12 & 0.09 & 0.38 & 0.43 & 0.25 \\
\hline \# of Total Country Observations & 1,086 & 1,071 & 1,880 & 1,382 & 1,278 & 2,118 & 2,581 & 1,886 & 438 & 3,092 & 1,333 & 18,145 \\
\hline
\end{tabular}

Table 2: Types of Mismatch by Entry Mode, \%

\begin{tabular}{|l|c|c|c|c|c|}
\hline & Over-Educated Only & Over-Skilled Only & Severely Mismatched & Mismatched & Total \\
\hline Advertisement & 0.19 & 0.15 & 0.17 & 0.17 & 0.15 \\
\hline Public Employment Agency & 0.06 & 0.05 & 0.08 & 0.06 & 0.05 \\
\hline Private Employment Agency & 0.09 & 0.07 & 0.15 & 0.11 & 0.05 \\
\hline Internet & 0.05 & 0.09 & 0.04 & 0.06 & 0.06 \\
\hline Contacted Employer Directly & 0.19 & 0.20 & 0.17 & 0.18 & 0.20 \\
\hline Approached by Employer & 0.08 & 0.08 & 0.05 & 0.07 & 0.10 \\
\hline Higher Education Work Placement & 0.08 & 0.08 & 0.03 & 0.06 & 0.10 \\
\hline Family/Friends & 0.18 & 0.15 & 0.25 & 0.20 & 0.13 \\
\hline Help from Higher Education & 0.04 & 0.06 & 0.03 & 0.04 & 0.06 \\
\hline Other & 0.04 & 0.07 & 0.04 & 0.05 & 0.08 \\
\hline Through Previous Work & 0.01 & 0.00 & 0.01 & 0.01 & 0.00 \\
\hline Total & 1.00 & 1.00 & 1.00 & 1.00 & 1.00 \\
\hline \# & 1,254 & 1,439 & 1,793 & 4,486 & 16,623 \\
\hline
\end{tabular}


Table 3: Distribution of Vocational Course by Country

\begin{tabular}{|c|c|c|c|}
\hline & Vocational & Non-Vocational & $\#$ \\
\hline Austria & 0.27 & 0.73 & 1,086 \\
\hline Belgium & 0.30 & 0.70 & 1,071 \\
\hline Finland & 0.62 & 0.38 & 1,880 \\
\hline France & 0.24 & 0.76 & 1,382 \\
\hline Germany & 0.30 & 0.70 & 1,278 \\
\hline Italy & 0.29 & 0.71 & 2,118 \\
\hline Netherlands & 0.57 & 0.43 & 2,581 \\
\hline Norway & 0.60 & 0.40 & 1,886 \\
\hline Portugal & 0.44 & 0.56 & 438 \\
\hline Spain & 0.24 & 0.76 & 3,092 \\
\hline UK & 0.27 & 0.73 & 1,333 \\
\hline Total & 0.39 & 0.61 & 18,145 \\
\hline
\end{tabular}

Table 4: Entry Modes - Probit and PSM Estimates for Mismatch

\begin{tabular}{|c|c|c|c|c|c|}
\hline $\begin{array}{l}\text { Entry Mode Variables } \\
\text { (Base case: Contacted Employer Directly) }\end{array}$ & $\begin{array}{l}\text { Probit } \\
(n=13,180)\end{array}$ & $\begin{array}{l}\text { PSM } \\
\text { (ATT) }\end{array}$ & $\begin{array}{l}\text { Pseudo R2 } \\
\text { (Pre) }\end{array}$ & $\begin{array}{l}\text { Pseudo R2 } \\
\text { (Post) }\end{array}$ & MHbounds \\
\hline Advert & $\begin{array}{l}0.06^{* * *} \\
(0.015)\end{array}$ & $\begin{array}{l}0.04^{* * *} \\
(0.012)\end{array}$ & $0.068 * * *$ & 0.004 & 1.20 \\
\hline Public Employment Agency & $\begin{array}{l}0.06 * * * \\
(0.021)\end{array}$ & $\begin{array}{l}0.05^{* * *} \\
(0.020)\end{array}$ & $0.116^{* * *}$ & 0.016 & 1.25 \\
\hline Private Employment Agency & $\begin{array}{l}0.18^{* * *} \\
(0.023)\end{array}$ & $\begin{array}{l}0.20^{* * *} \\
(0.020)\end{array}$ & $0.171 * * *$ & 0.013 & 3.20 \\
\hline Internet & $\begin{array}{c}-0.02 \\
(0.017)\end{array}$ & $\begin{array}{l}-0.03 * * \\
(0.015)\end{array}$ & $0.056 * * *$ & 0.011 & 1.05 \\
\hline Approached by Employer & $\begin{array}{c}-0.06 * * * \\
(0.020)\end{array}$ & $\begin{array}{c}-0.07^{* * *} \\
(0.011)\end{array}$ & $0.031 * * *$ & 0.005 & 1.65 \\
\hline Higher Education Work Placement & $\begin{array}{c}-0.08^{* * *} \\
(0.013)\end{array}$ & $\begin{array}{c}-0.10^{* * *} \\
(0.011)\end{array}$ & $0.070 * * *$ & 0.003 & 1.80 \\
\hline Family/Friends & $\begin{array}{l}0.06^{* * *} \\
(0.015)\end{array}$ & $\begin{array}{l}0.08^{* * *} \\
(0.013)\end{array}$ & $0.071 * * *$ & 0.005 & 1.85 \\
\hline Help from Higher Education & $\begin{array}{c}-0.07 * * * \\
(0.016)\end{array}$ & $\begin{array}{c}-0.08^{* * *} \\
(0.014)\end{array}$ & $0.085^{* * *}$ & 0.008 & 1.65 \\
\hline Other (inc. Previous Work) & $\begin{array}{c}-0.05^{* * *} \\
(0.016)\end{array}$ & $\begin{array}{c}-0.06 * * * \\
(0.013)\end{array}$ & $0.053^{* * *}$ & 0.008 & 1.50 \\
\hline
\end{tabular}


Table 5: Entry Mode - PSM Estimates for Different Forms of Mismatch

\begin{tabular}{|l|c|c|c|}
\hline $\begin{array}{l}\text { Entry Mode Variables } \\
\text { (Base case: Contacted Employer Directly) }\end{array}$ & Over-education Only & Over-skilled Only & Severely Mismatched \\
\hline Advert & $0.03^{* * *}$ & 0.00 & 0.01 \\
& $(0.007)$ & $(0.007)$ & $(0.008)$ \\
\hline Public Employment Agency & 0.02 & -0.01 & $0.05^{* *}$ \\
& $(0.012)$ & $(0.12)$ & $(0.015)$ \\
\hline Private Employment Agency & $0.02^{*}$ & $0.03^{* *}$ & $0.14^{* * *}$ \\
& $(0.013)$ & $(0.014)$ & $(0.018)$ \\
\hline Internet & $-0.02^{* *}$ & $0.02^{* *}$ & $-0.04^{* * *}$ \\
& $(0.008)$ & $(0.011)$ & $(0.009)$ \\
\hline Approached by Employer & $-0.02^{* *}$ & $-0.02^{* *}$ & $-0.04^{* * *}$ \\
& $(0.007)$ & $(0.011)$ & $(0.007)$ \\
\hline Higher Education Work Placement & $-0.02^{* * *}$ & $-0.02^{* *}$ & $-0.06^{* * *}$ \\
& $(0.007)$ & $(0.007)$ & $(0.006)$ \\
\hline Family/Friends & $0.02^{* *}$ & 0.01 & $0.06^{* * *}$ \\
& $(0.007)$ & $(0.008)$ & $(0.010)$ \\
\hline Help from Higher Education & $-0.02^{* * *}$ & -0.01 & $-0.05^{* * *}$ \\
& $(0.008)$ & $(0.010)$ & $(0.008)$ \\
\hline Other (inc. Previous Work) & $-0.03^{* * *}$ & 0.00 & $-0.03^{* * *}$ \\
& $(0.007)$ & $(0.009)$ & $(0.008)$ \\
\hline
\end{tabular}


Table 6: Entry Mode - PSM Estimates for Mismatched by Search Duration

\begin{tabular}{|c|c|c|}
\hline $\begin{array}{l}\text { Entry Mode Variables } \\
\text { (Base case: Contacted Employer Directly) }\end{array}$ & $\begin{array}{c}\text { PSM } \\
\text { Search 0-2 Months } \\
(n=7,253)\end{array}$ & $\begin{array}{c}\text { PSM } \\
\text { Search 3+ Months } \\
(n=5,927)\end{array}$ \\
\hline Advert & $\begin{array}{l}0.06^{* * *} \\
(0.016)\end{array}$ & $\begin{array}{l}0.03^{* *} \\
(0.017)\end{array}$ \\
\hline Public Employment Agency & $\begin{array}{l}0.07^{* *} \\
(0.056)\end{array}$ & $\begin{array}{c}0.04 \\
(0.026)\end{array}$ \\
\hline Private Employment Agency & $\begin{array}{l}0.21^{* * *} \\
(0.027)\end{array}$ & $\begin{array}{l}0.19 * * * \\
(0.030)\end{array}$ \\
\hline Internet & $\begin{array}{l}-0.04 * \\
(0.021)\end{array}$ & $\begin{array}{c}-0.03 \\
(0.022)\end{array}$ \\
\hline Approached by Employer & $\begin{array}{c}-0.07^{* * *} \\
(0.013)\end{array}$ & $\begin{array}{c}-0.06 * * * \\
(0.021)\end{array}$ \\
\hline Higher Education Work Placement & $\begin{array}{c}-0.09 * * * \\
(0.015)\end{array}$ & $\begin{array}{c}-0.11^{* * *} \\
(0.018)\end{array}$ \\
\hline Family/Friends & $\begin{array}{l}0.07^{* * *} \\
(0.017)\end{array}$ & $\begin{array}{l}0.10^{* * *} \\
(0.019)\end{array}$ \\
\hline Help from Higher Education & $\begin{array}{l}-0.08^{* * *} \\
(0.017)\end{array}$ & $\begin{array}{c}-0.07 * * \\
(0.024)\end{array}$ \\
\hline Other (inc. Previous Work) & $\begin{array}{c}-0.04 * * * \\
(0.017)\end{array}$ & $\begin{array}{c}-0.07^{* * *} \\
(0.020)\end{array}$ \\
\hline
\end{tabular}


Table 7: Course Composition - PSM Estimates for Mismatch

\begin{tabular}{|c|c|c|c|c|c|}
\hline $\begin{array}{l}\text { Course Composition Variables } \\
\text { (modes emphasised) }\end{array}$ & $\begin{array}{c}\text { Probit } \\
(n=11,625)\end{array}$ & $\begin{array}{l}\text { PSM } \\
\text { (ATT) }\end{array}$ & $\begin{array}{l}\text { Pseudo R2 } \\
\text { (Pre) }\end{array}$ & $\begin{array}{l}\text { Pseudo R2 } \\
\text { (Post) }\end{array}$ & MHbounds \\
\hline Lectures & $\begin{array}{c}0.00 \\
(0.010)\end{array}$ & $\begin{array}{c}-0.00 \\
(0.009)\end{array}$ & $0.091 * * *$ & 0.002 & - \\
\hline Group Assignments & $\begin{array}{l}-0.00 \\
(0.014)\end{array}$ & $\begin{array}{c}-0.00 \\
(0.012)\end{array}$ & $0.059 * * *$ & 0.004 & - \\
\hline Research Projects & $\begin{array}{c}0.01 \\
(0.024)\end{array}$ & $\begin{array}{c}0.01 \\
(0.021)\end{array}$ & $0.055 * * *$ & 0.040 & - \\
\hline Work Placement & $\begin{array}{c}-0.09 * * * \\
(0.017)\end{array}$ & $\begin{array}{c}-0.09 * * * \\
(0.011)\end{array}$ & $0.139 * * *$ & 0.005 & 2.00 \\
\hline Facts and Practical Knowledge & $\begin{array}{c}-0.06 * * * \\
(0.014)\end{array}$ & $\begin{array}{c}-0.06 * * * \\
(0.012)\end{array}$ & $0.056 * * *$ & 0.003 & 1.35 \\
\hline Theories and Paradigms & $\begin{array}{c}0.02 \\
(0.012)\end{array}$ & $\begin{array}{l}0.02^{*} \\
(0.011)\end{array}$ & $0.068 * * *$ & 0.001 & - \\
\hline Teacher & $\begin{array}{c}0.02 \\
(0.013)\end{array}$ & $\begin{array}{c}0.02 \\
(0.012)\end{array}$ & $0.074 * * *$ & 0.002 & - \\
\hline Project/Problem-Based Learning & $\begin{array}{c}-0.02 \\
(0.017)\end{array}$ & $\begin{array}{l}-0.03^{* *} \\
(0.014)\end{array}$ & $0.054 * * *$ & 0.008 & 1.40 \\
\hline Written Assignments & $\begin{array}{l}0.03 * * \\
(0.013)\end{array}$ & $\begin{array}{l}0.03^{* * *} \\
(0.011)\end{array}$ & $0.098 * * *$ & 0.002 & 1.25 \\
\hline Oral Presentations & $\begin{array}{l}0.03^{*} \\
(0.016)\end{array}$ & $\begin{array}{c}0.02 \\
(0.014)\end{array}$ & $0.078 * * *$ & 0.006 & - \\
\hline Multiple Choice Exams & $\begin{array}{l}0.03 * * \\
(0.013)\end{array}$ & $\begin{array}{c}0.01 \\
(0.019)\end{array}$ & $0.242 * * *$ & 0.019 & - \\
\hline
\end{tabular}


Table 8: Course Composition - PSM Estimates for Different Form of Mismatch

\begin{tabular}{|c|c|c|c|}
\hline $\begin{array}{l}\text { Course Composition Variables } \\
\text { (modes emphasised) }\end{array}$ & $\begin{array}{l}\text { Over-Education Only } \\
\qquad(n=11,573)\end{array}$ & $\begin{array}{l}\text { Over-Skilled Only } \\
\quad(n=11,602)\end{array}$ & $\begin{array}{l}\text { Severely Mismatched } \\
\quad(n=11,625)\end{array}$ \\
\hline Lectures & $\begin{array}{l}-0.00 \\
(0.005)\end{array}$ & $\begin{array}{c}0.00 \\
(0.006)\end{array}$ & $\begin{array}{l}-0.00 \\
(0.006)\end{array}$ \\
\hline Group Assignments & $\begin{array}{l}0.02 * * \\
(0.008)\end{array}$ & $\begin{array}{l}-0.02^{* *} \\
(0.007)\end{array}$ & $\begin{array}{c}-0.01 \\
(0.008)\end{array}$ \\
\hline Research Projects & $\begin{array}{c}0.00 \\
(0.013)\end{array}$ & $\begin{array}{l}-0.00 \\
(0.013)\end{array}$ & $\begin{array}{c}0.01 \\
(0.015)\end{array}$ \\
\hline Work Placement & $\begin{array}{l}-0.01^{*} \\
(0.007)\end{array}$ & $\begin{array}{c}-0.04 * * * \\
0.005\end{array}$ & $\begin{array}{c}-0.04 * * * \\
0.007\end{array}$ \\
\hline Facts and Practical Knowledge & $\begin{array}{l}-0.01^{*} \\
(0.007)\end{array}$ & $\begin{array}{c}-0.02^{* * *} \\
(0.007)\end{array}$ & $\begin{array}{c}-0.03^{* * *} \\
(0.008)\end{array}$ \\
\hline Theories and Paradigms & $\begin{array}{l}-0.01 * * \\
(0.006)\end{array}$ & $\begin{array}{l}0.02^{* * *} \\
(0.007)\end{array}$ & $\begin{array}{c}0.01 \\
(0.007)\end{array}$ \\
\hline Teacher & $\begin{array}{c}0.01 \\
(0.007)\end{array}$ & $\begin{array}{c}0.00 \\
(0.007)\end{array}$ & $\begin{array}{c}0.01 \\
(0.009)\end{array}$ \\
\hline Project/Problem-Based Learning & $\begin{array}{c}0.02 \\
(0.010)\end{array}$ & $\begin{array}{c}-0.01 \\
(0.009)\end{array}$ & $\begin{array}{l}-0.04 * * * \\
(0.014)\end{array}$ \\
\hline Written Assignments & $\begin{array}{l}0.01 * \\
(0.007)\end{array}$ & $\begin{array}{l}-0.00 \\
(0.007)\end{array}$ & $\begin{array}{l}0.02 * * \\
(0.008)\end{array}$ \\
\hline Oral Presentations & $\begin{array}{c}0.03^{* * *} \\
(0.009)\end{array}$ & $\begin{array}{c}0.00 \\
(0.009)\end{array}$ & $\begin{array}{l}-0.00 \\
(0.010)\end{array}$ \\
\hline Multiple Choice Exams & $\begin{array}{c}0.01 \\
(0.012)\end{array}$ & $\begin{array}{c}0.01 \\
(0.012)\end{array}$ & $\begin{array}{c}-0.00 \\
(0.014)\end{array}$ \\
\hline
\end{tabular}


Table 9: Probit Estimates for Mismatch (Vocational and Non-Vocational)

\begin{tabular}{|l|l|l|}
\hline $\begin{array}{l}\text { Course Composition Variables } \\
\text { (Modes Emphasised) }\end{array}$ & $\begin{array}{l}\text { Vocational } \\
(\mathbf{n}=\mathbf{4 , 5 0 9 )}\end{array}$ & $\begin{array}{l}\text { Non-Vocational } \\
(\mathbf{n}=\mathbf{7 , 1 1 6})\end{array}$ \\
\hline Lectures & 0.01 & -0.01 \\
& $(0.014)$ & $(0.014)$ \\
\hline Group Assignments & -0.01 & 0.00 \\
& $(0.016)$ & $(0.021)$ \\
\hline Research Projects & -0.01 & 0.04 \\
& $(0.028)$ & $(0.036)$ \\
\hline Work Placement & $-0.03^{* *}$ & $-0.12^{* * *}$ \\
& $(0.014)$ & 0.021 \\
\hline Facts and Practical Knowledge & $-0.06^{* * *}$ & -0.03 \\
& $(0.014)$ & $(0.025)$ \\
\hline Theories and Paradigms & 0.02 & 0.01 \\
& $(0.020)$ & $(0.015)$ \\
\hline Teacher & 0.01 & 0.02 \\
& $(0.020)$ & $(0.017)$ \\
\hline Project/Problem-Based Learning & 0.01 & $-0.05^{* *}$ \\
& $(0.020)$ & $(0.026)$ \\
\hline Written Assignments & 0.01 & $0.03^{*}$ \\
& $(0.018)$ & $(0.017)$ \\
\hline Oral Presentations & 0.03 & $0.04^{*}$ \\
& $(0.020)$ & $(0.023)$ \\
\hline Multiple Choice Exams & -0.02 & 0.05 \\
& $(0.024)$ & $(0.029)$ \\
\hline & & \\
\hline
\end{tabular}


Figures

Figure 1: Dose Response Models for Vocational Education by Gender

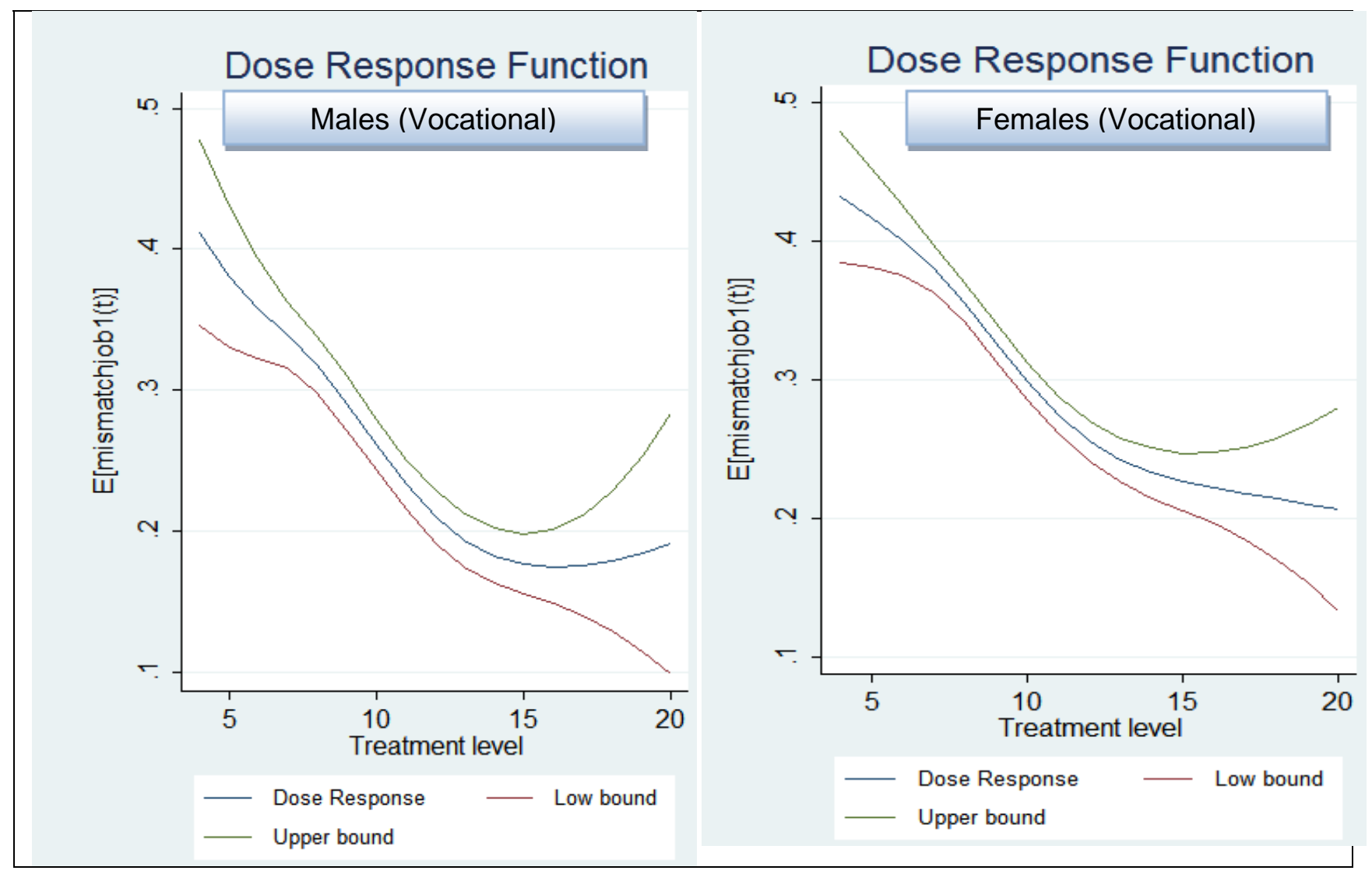

